\title{
OS LIMITES ENTRE A EXPLORAÇÃO E A ESCRAVIDÃO NO CICLO DA CERA DE CARNAÚBA
}

\section{THE LIMITS BETWEEN EXPLORATION AND SLAVERY IN THE CARNAUBA WAX CYCLE}

\author{
Cristiana Costa da Rocha*
}

\section{RESUMO}

A cera de carnaúba passou a ocupar lugar de destaque no conjunto das exportações do Piauí nos primeiros anos do século XX, e teve seus tempos áureos a partir de 1940, quando o estado superou o Ceará, até então considerado o principal produtor da cera. Embora inovações tecnológicas tenham sido introduzidas na preparação da cera, para extração do pó, os trabalhadores do nosso tempo ainda executam atividades já consideradas rudimentares nos seus tempos áureos. Trata-se de um trabalho árduo, braçal, descrito pelos nossos entrevistados como passíveis de danos irreversíveis à saúde. Além dos danos causados à saúde, esses processos resultam, ainda, em perdas no plano ecológico, pelo excesso de cortes a que são submetidas as carnaubeiras. No ano de 2014, foi flagrado o primeiro grupo de trabalhadores em condição de trabalho escravo em áreas arrendadas para a extração do pó da carnaúba no Estado. A partir das experiências de famílias de trabalhadores extrativistas, pretendemos compreender os mecanismos que favorecem o processo de naturalização da exploração nesse tipo de atividade, claramente toleradas por grupos tradicionais e passadas de geração a geração, e os limites entre a exploração e a escravidão pensados tanto pelos trabalhadores como pelo Estado. Além de fontes orais, foram analisadas fontes escritas, acessadas em acervos da Superintendência Regional do Trabalho e Emprego - SRTE, Ministério Público do Trabalho - MPT. A pesquisa foi iniciada no âmbito da Rede de Ação Integrada para Combater a Escravidão - Raice, CPT/CDVBH-CB, e continuada através do Programa de Bolsa de Iniciação Científica - PIBIC.

\begin{abstract}
Carnauba wax came to occupy a prominent place in the set of exports of Piaui in the early years of the twentieth century and had its golden days from 1940, when the state surpassed Ceara until then considered the main producer of wax. Although technological innovations have been introduced in the preparation of wax for dust extraction, workers of our time still perform activities already considered rudimentary in their golden age. This is hard, manual work, described by our interviewees as irreversible damage to health. In addition to the damage caused to health, these processes also result in ecological losses due to the excessive cuts to which palms are subjected. In 2014, the first group of slave laborers in areas leased for the extraction of carnauba dust in the state was caught. From the experiences of families of extractive workers we intend to understand the mechanisms that favor the naturalization process of exploration in this type of activity, clearly tolerated by traditional groups and passed from generation to generation, and the boundaries between exploration and slavery thought by both workers as by the government. In addition to oral sources, written sources were also analyzed, accessed in collections of the Superintendencia Regional do Trabalho e Emprego - SRTE, Ministério Público do Trabalho-MPT. The research was initiated under the Rede de Ação Integrada para Combater a Escravidão - Raice - Raice, $\mathrm{CPT} / \mathrm{CDVBH}-\mathrm{CB}$, and continued through the Programa de Bolsa de Iniciação Científica - PIBIC ${ }^{1}$.
\end{abstract}

* Doutora em História Social pela Universidade Federal Fluminense; Professora Adjunta III do Curso de História da Universidade Estadual do Piauí - UESPI; Professora do Programa de PósGraduação, Mestrado Interdisciplinar em Sociedade e Cultura da Universidade Estadual do Piauí. E-mail: cristianacrocha@gmail.com.

$1 \mathrm{CDVDH} / \mathrm{CB}, 2017$. 
PALAVRAS-CHAVE: Extrativismo da cera. Trabalho escravo. Exploração no trabalho.
KEYWORDS: Wax extractivism. Slavery. Exploration at work.

\section{INTRODUÇÃO}

A cera de carnaúba passou a ocupar lugar de destaque no conjunto das exportações do Piauí nos primeiros anos do século XX, e teve seus tempos áureos a partir de 1940, quando o Estado superou o Ceará, até então considerado o principal produtor da cera. Naquele período, o caráter oscilante da produção foi atribuído à natureza extrativa do produto, que depende da oferta natural das plantas produtoras, e também ao caráter rudimentar das técnicas adotadas, que resultava no desperdício da matéria-prima e baixa produtividade ${ }^{2}$. Da retirada da palha ao beneficiamento da cera de carnaúba, exige-se trabalho árduo, braçal, descrito pelos extrativistas que lidam com a retirada da palha e extração do pó cerífero como passível de danos irreversíveis à saúde.

As condições de trabalho que permeiam a unidade de exploração da carnaúba atravessaram o século e se reproduzem nos dias atuais. No ano de 2014, foi realizada a primeira ação de fiscalização do Ministério Público do Trabalho - MPT/PI e Superintendência Regional do Trabalho e Emprego STRE/PI e flagrado o primeiro grupo de trabalhadores em condição de trabalho escravo em áreas arrendadas para a extração do pó da carnaúba no estado. Para além de problemas operacionais e logísticos dos organismos responsáveis, a descoberta tardia em relação ao uso de trabalho escravo na extração do pó da carnaúba se deve à naturalização da exploração no trabalho, historicamente tolerada por grupos tradicionais e passada de geração a geração. Diante disso, apresentamos as seguintes questões: $\mathrm{O}$ que é escravidão e, ou, exploração, para estes sujeitos? Que elementos históricos favoreceram a permanência das formas seculares de exploração desses trabalhadores? De que modo eles se percebem em contexto de ampliação das ações do Estado para combater a exploração e a escravização?

Não é uma tarefa fácil encontrar sujeitos comuns, homens e mulheres pobres, em fontes oficiais, e nem sempre isso é possível e, ao invisibilizar as ações comuns desses sujeitos, esse tipo de fonte se volta para os desdobramentos de suas ações em valores econômicos. Nesse sentido, a documentação consultada nos deu indícios importantes sobre os modos de organização desses grupos em torno da atividade de extração do pó da carnaúba. Para este estudo, realizamos levantamento e análise de fontes arquivísticas, Mensagens de Governo, Relatórios e Imagens, acessadas no Arquivo Público do Estado do Piauí (Casa Anísio Freitas), Departamento Nacional de Obras Contra as Secas - Dnocs/ PI, Instituto Brasileiro de Geografia e Estatística - IBGE, Superintendência

2 QUEIROZ, 1998. 
Regional do Trabalho e Emprego - SRTE e Ministério Público do Trabalho - MPT. Além disso, produzimos fontes orais a partir de entrevistas com trabalhadores, agentes da sociedade civil e representantes do Estado, iniciadas no âmbito da Rede de Ação Integrada para Combater a Escravidão - Raice, CPT/ CDVBH-CB, no sentido de identificar regiões com seus respectivos municípios e respectivas comunidades, nos estados do Piauí, Maranhão, Tocantins e Pará, que apresentavam situação de vulnerabilidade ao aliciamento ou já tenham vivenciado a condição de trabalho escravo na região de origem e, ou como migrantes, em outras regiões do país ${ }^{3}$.

\section{OS TRABALHADORES DO EXTRATIVISMO}

Em Relatório do Governo do Piauí (1931-1935), apresentado ao presidente Getúlio Vargas, o interventor federal Landry Sales Gonçalves apresentou, em tom de denúncia, uma breve característica das condições em que a cera de carnaúba era produzida no estado. Dado a relevância para a economia do estado no contexto, ele atribuiu ao sistema de arrendamento a centralidade da problemática quanto à exploração da palmeira. Diz o relatório:

CÊRA DA CARANAÚBA: - A principal fonte de rendas das fazendas é, incontestável, a cêra de carnaúba - produto valiosíssimo - entregue, até então, a arrendatários inexperientes, que exploravam a seu talante os carnaúbaes, até a exhaustão. Sem qualquer somma de protecção á preciosa palmeira e ao seu produto, era contristador o estado de abandono dos carnaúbaes a atestar a criminosa incúria dos que, por longos annos, viveram á custa de seus magníficos proventos ${ }^{4}$.

As unidades de exploração formadas por arrendatários e parceiros ${ }^{5}$ eram predominantes em um contexto em que o extrativismo vegetal ocupava maiores extensões territoriais. Os relatórios dos Governos entre os anos de 1930 e $1950^{6}$ apresentam, em ordem de importância, a cera de carnaúba, o babaçu, algodão e a mamona, como as principais fontes de sustentação econômica do estado. Por sua vez, os relatórios também evidenciam preocupação quanto ao uso de técnicas rudimentares nessas atividades.

Em 1942, Leônidas de Castro Melo, então interventor do estado, informou a aquisição de 5 "TITAN" nas Fazendas Estaduais, para beneficiamento das palmas das carnaubeiras, a que atribui o aumento da produção. A mecanização era pensada, dentre outros aspectos, como uma forma de "controle do trabalho". Para tanto, é preciso considerar que o homem rural possui peculiaridades

\footnotetext{
3 CDVDH, CPT, 2017.

4 PIAUÍ, 1931-1935, p 114.

5 O arrendatário ou inquilino do proprietário da terra, pagava uma renda pelo seu uso que podia ser feita em trabalho, ou em espécie, nesse caso o arrendatário, ou parceiro, entregava parte da sua produção ao proprietário.

6 Nesse período a produção da cera da carnaúba atingiu seus tempos áureos e declínio.
} 
quanto à forma de lidar com o tempo e disciplina no trabalho. No caso em estudo, a disciplina é comumente exercida através de um tipo de deferência do trabalhador para com o patrão ou dono da terra, viabilizada pelo sistema de parceria. Em linhas gerais, o tipo de relação estabelecida entre dono da terra/ patrão e trabalhador no seio de uma comunidade rural evidencia um estilo paternalista de controle e disciplina de trabalhadores pobres. Em uma passagem do artigo intitulado "Patrícios e Plebeus", Thompson comenta:

As ocasiões de patronagem de aristocracia e da gentry certamente merecem atenção: esse lubrificante social dos gestos poderia, com bastante facilidade, fazer os mecanismos de poder e exploração girarem mais suavemente. Os pobres, habituados à sua posição irrevogável, eram frequentemente transformados, pela sua própria boa índole, em cúmplices de sua própria opressão: um ano de provisões escassas podia ser compensado por uma generosa doação no $\mathrm{Natal}^{7}$.

A interpretação do autor nos possibilita pensar os mecanismos históricos de aceitação por parte das populações pobres trabalhadoras aos desmandos dos patrões, que, através do controle, submissão e ilegalidade se mantêm no poder por gerações sucessivas.

No caso do trabalho exercido no Ciclo da Cera de Carnaúba, o processo desde a retirada da palha à extração do pó da carnaúba se dá de forma sincronizada, interdependente e atende a uma temporalidade peculiar, por ser executada somente em período de estiagem. Nesse sentido, trata-se de um tipo de atividade que se fundamenta historicamente em normas, obrigações sociais e valores peculiares aos interesses dos trabalhadores e que, ao se confrontarem com a lógica do mercado em larga escala voltado para a exportação, sofreu entraves, dada a falta de habilidade dos comerciantes, industriais e Estado em avançar na construção de metas essenciais para o seu desenvolvimento.

A preocupação com o modelo tradicional de exploração do pó de carnaúba aparece em trechos das Mensagens de Governo, ao tempo em que apresentam como entrave a inadequação dos trabalhadores da cera à introdução de métodos modernizantes. E, por se tratar de uma atividade que atende a normas específicas e comuns ao trabalho no campo, as tentativas de introdução de estratégias de controle e disciplina tendem a sofrer adequações a partir da mediação entre patrões e trabalhadores, sobre os quais pesa a condição de dependência em relação à terra para o trabalho, reforçado pelo predomínio do sistema de parceria na atividade extrativa.

A perspectiva de libertação do sistema de parceria é recorrente na fala dos entrevistados, que se reconhecem como cativos da terra. Em vistas disso, o crescimento da economia coube às grandes e médias propriedades, através do arrendamento e da parceria, e não ao avanço da grande fronteira livre.

7 THOMPSON, 1998, p. 49. 
Os lavradores sem terra continuavam presos e condicionados à suas próprias condições de trabalho, seja parceria, arrendamento, ou trabalho assalariado. Em qualquer dessas condições, o proprietário procurava obter o máximo do resultado do trabalho.

O extrativismo da cera é apresentado nas fontes como uma atividade dependente dos contratos de arrendamento e parceria agrária, e pode ser evidenciado com frequência nas fontes oficiais, a esse respeito:

FAZENDAS ESTADUAIS - De acordo com dispositivos de nossa Constituição, os carnaubais e maniçobais das Fazendas foram postos sem concorrência pública, sendo os mesmos arrendados.

O arrendamento dos carnaubais foi pago em espécie, com 15.500 quilos de cera flor e 62.000 ditos de cera parda, num total de 77.500 quilos, o que corresponde a 77,09\% da produção média anual verificada no último decênio. Os maniçobais foram arrendados pela quantia de....... $\mathrm{Cr} \$ 17.819,00 .^{8}$

Os anos que sucedem a crise da produção da cera foram marcados pelo estado de penúria da população do Estado, atingindo em particular a população rural e a produção agrícola. A expulsão do homem do campo, evidenciada também em discurso oficial do Governo no ano de 1948, ao relatar a decadência da Colônia Agrícola David Caldas.

COLÔNIA AGRÍCOLA "DAVID CALDAS" - A Colônia Agrícola "David Caldas", pelo abandono a que the relegaram caiu em verdadeira decadência. Quem a visita nos tempos atuais e a compara com os primeiros dias de sua fundação, sente-se constrangido, por ver frustrado, um plano, que prometia resultados compensadores, na fixação do homem à terra. Pelo que se sabe ali inverteu o Governo, em anos anteriores, grandes somas e é doloroso constar o fracasso em que escarmento das gerações, comportavam uma análise, um estudo minucioso em que apurassem as causas da sua ruína. ${ }^{9}$

Como no Piauí, o contexto de penúria e calamidade com indícios de expulsão do homem do campo para a cidade ou para outras regiões ou estados vizinhos, são condições comuns apresentadas em outras regiões do Nordeste. As fontes oficiais consultadas para este estudo evidenciam a insatisfação dos governantes e elite local em relação às formas consideradas rudimentares de extração do pó da carnaúba, da derrubada da palha ao beneficiamento da cera, cujas técnicas resultariam em desperdício da matéria-prima e baixa produtividade. Além disso, atribuíam a tais técnicas, a fragilidade da economia.

As carnaubeiras aparecem em todo o estado e, embora a aridez do solo seja uma condição necessária à própria formação do pó cerífero, elas ocorrem principalmente em áreas sujeitas a inundações durante alguns meses do ano. Por sua vez, a derrubada da palha se dá em períodos posteriores, de estiagem.

8 PIAUÍ, 1952, p. 112.

9 
Embora inovações tecnológicas tenham sido introduzidas na preparação da cera, para extração do pó, os trabalhadores do nosso tempo ainda executam atividades já consideradas rudimentares nos seus tempos áureos. A cadeia produtiva da cera de carnaúba envolve as seguintes etapas: corte, realizado pelo vareiro/foreiro, que utiliza varas de bambu com uma foice presa em umas das extremidades para derrubar a palmeira; em seguida, o desganchador/gueiro colhe as palhas que são aparadas e enfeixadas pelo aparador; na etapa seguinte é realizado o transporte pelos tangedores/carregadores até o lastro; o lastreiro espalha as folhas para secagem por cerca de seis a oito dias; após a secagem se inicia o processo de retirada do pó cerífero das palhas com utilização de máquinas denominadas "bate-palha"; a etapa final é a industrialização para extração da cera presente no pó ${ }^{10}$. Além dos danos causados à saúde, esses processos resultam ainda em perdas no plano ecológico, pelo excesso de cortes a que são submetidas as carnaubeiras.

As duas imagens que se seguem datam do ano de 1957 em Cabeceiras, que, na circunstância, era povoado do município de Barras no Norte do estado. As imagens são bastante reveladoras acerca da organização da mão de obra familiar em torno da atividade da cera da carnaúba.

\section{Imagem 1}

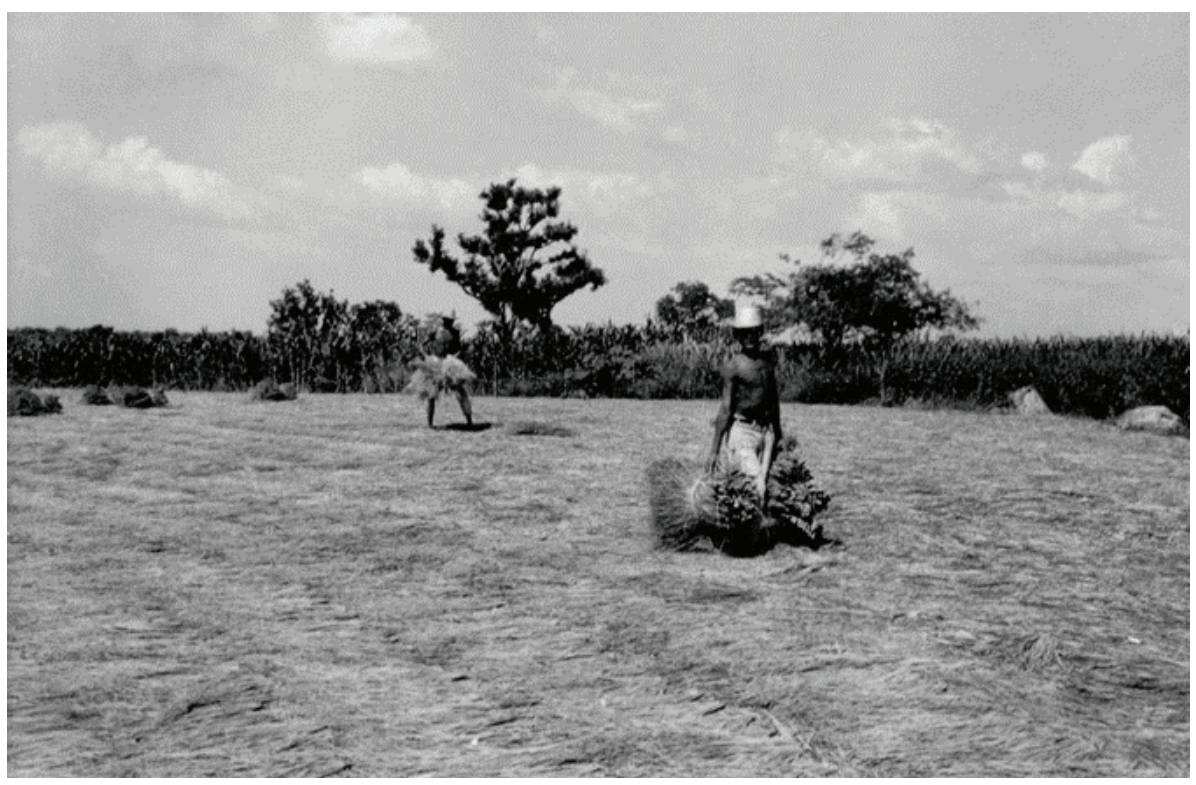

Imagem 01: Homem carregando palhas de carnaúba em 1957. Cabeceiras, PI (FONTE: IBGE)

10 STRE, 2014, p.16. 
Os danos causados à saúde dos trabalhadores da cera eram abordados pelas autoridades locais, que faziam eco diante da ameaça de alastramento de doenças infectocontagiosas, como a tuberculose. $\mathrm{O}$ fragmento abaixo refere-se à fala do Delegado Agenor Martins e foi retirado das páginas do Almanaque da Parnaíba, diz ele:

De todas as moléstias endêmicas, o paludismo constitui nesta "Divisão Sanitária" o maior flagelo, ceifando anualmente centenas de preciosas vidas, arruinando a saúde de milhares de pessoas, formando um exército de inflamados (expressão da terra) de homens pálidos, fracos, sem ânimo, sem ideal e sem vida, incapazes para o trabalho remunerador. ${ }^{11}$

O contexto de debate sobre as condições a que estavam submetidos esses sujeitos, embora por vezes fragmentado, pode ser evidenciado também na literatura da época, e nos permite pensar o contexto degradante e de exploração a que eram submetidos os trabalhadores extrativistas.

O "pó" ou a cera "in-natura", tal como se desaloja das palhas, tanto quanto as poeiras industriais de carvão, sílico, algodão e ferro, pela inalação contínua de vários meses em meios reclusos, penetra no íntimo dos pulmões, atapelando [sic.] os alvéolos, prejudicando a respiração, restringindo o fenômeno vital da hematose pulmonar e, em última análise, pela pneumoconiose ocasionada, predispondo a uma série de doenças pulmonares, onde a tuberculose assume o papel mais importante da posologia das zonas de carnaubais. ${ }^{12}$

A questão da saúde do trabalhador compõe o quadro de discussão de implementação das primeiras leis trabalhistas no Brasil, em um contexto que marca o início da intervenção do Estado nos assuntos, tratando-se de questões, particularmente, ligadas ao acidente no trabalho. Em contexto geral, são medidas que partiram de interesse internacional definidos após a Primeira Guerra Mundial e assinatura do Tratado de Versalhes (1919), que recomendou a instituição do Direito do Trabalho no Brasil. No que versa sobre o acidente do trabalho, a Constituição Federal de 1934 diz:

Art. $1^{\circ}$ Considera-se acidente do trabalho, para os fins da presente lei, toda lesão corporal, perturbação funcional, ou doença produzida pelo exercício do trabalho ou em consequência dele, que determine a morta, ou a suspensão ou limitação, permanente ou temporária, total ou parcial, da capacidade para o trabalho. ${ }^{13}$

Nos jornais de circulação local no período, evidenciamos referências às condições de trabalho no estado que chamam atenção para os possíveis danos causados à saúde dos trabalhadores, como fadigas, acidentes e moléstias profissionais, causadas por excesso de carga horária ${ }^{14}$. Algumas notas se colocam

11 PARNAÍBA, 1937, p. 183.

12 MOTA. Apud FONTENELE, 2018.

13 BRASIL, 1934.

14 JORNAL O PIAUÍ 13 de junho de 1951 p. 02 
em consonância com o dispositivo legal vigente, a CLT. Por sua vez, pesa para nossas análises o caráter de informalidade que atravessa a atividade da cera, cuja mão de obra predominantemente exercida por trabalhadores rurais a torna invisível diante dos dispositivos legais vigentes. Além disso, é preciso considerar que há, sobretudo, uma invisibilidade em relação às condições a que eram, e ainda continuam, submetidos estes sujeitos.

Além das doenças às quais estão expostos, pelo ambiente inapropriado e longas horas de trabalho, a retirada da palha implica riscos de acidentes no trabalho, como lesões no rosto e várias partes do corpo, por se tratar de uma atividade exercida sem proteção. Embora recomendada por organismos internacionais, a exemplo da Convenção $\mathrm{n}^{\circ} 12$, de 1921, sobre a indenização por acidente do trabalhador agrícola, o alargamento desse benefício aos trabalhadores rurais se deu apenas no final do século passado através da Lei Acidentária, Lei $n^{\circ} 8.231 / 9$. O fato é que a Consolidação das Leis Trabalhistas - CLT, criada em 1943 pelo governo de Getúlio Vargas, cujos benefícios não se estendiam aos desempregados, trabalhadores rurais e domésticos, que não eram considerados cidadãos por não exercerem funções reconhecidas pela lei, contribuiu para a institucionalização da escravidão nas áreas rurais do país.

A crise evidenciada nos relatórios dos governos locais, como nas páginas dos jornais, se acentua nas condições de trabalho para o homem rural. Em relatório de governo de 1952, foram apresentadas medidas a serem direcionadas a estes sujeitos, são elas: Assistência Financeira; Assistência Médica; Habitação Rural; Armazenagem; Divisão de Propriedade; e Financiamento ${ }^{15}$. Ao tempo em que reafirmavam o apoio técnico e financeiro do Ministério da Agricultura às atividades agrícolas e extrativas, os aspectos tratados em tom de prioridade fazem repercutir as condições de vida e trabalho do homem do campo naquele contexto.

Chama-nos atenção, ainda, a proposta de divisão de propriedade. O relatório apresenta o seguinte fragmento: "o poder público loteará as terras agrícolas do seu domínio e desapropriará outras, onde necessário, para distribuição, mediante pagamento a prestação a longo prazo, criando núcleos de pequenas propriedades com centros de assistência técnica e financeira" ${ }^{16}$. $\mathrm{Na}$ circunstância descrita, as terras do estado estavam divididas nas seguintes categorias: "I - Terra dos carnaubais; II - Terras de babaçu; III - Terras Frescas de brejo para lavoura; IV - Terras de mata para a lavoura; e V- Terras de criação e lavoura (mixta)" ${ }^{17}$.

A referência à divisão das terras no relatório do governo diz respeito às áreas passíveis sujeitas à cobrança de impostos. $\mathrm{O}$ fato é que, a exploração

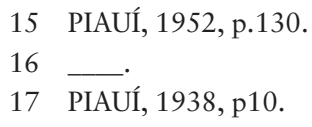


extrativa sempre esteve assentada em mão de obra barata e em terras cedidas pelos proprietários a moradores que paralelamente cultivavam suas roças na base do sistema de parceria ou arrendamento. Entre 1950 e 1970, parcelas de latifúndios foram entregues a famílias não proprietárias, que formavam roças para o cultivo de culturas temporárias e eram obrigadas a pagar renda e a prestar algum tipo de serviço ao proprietário. O domínio do latifúndio pecuarista ou extrativista foi substituído pelo predomínio de pequenas unidades de exploração, formadas por pequenos proprietários e posseiros (até 100 ha), arrendatários e parceiros ${ }^{18}$.

\section{Imagem 2}

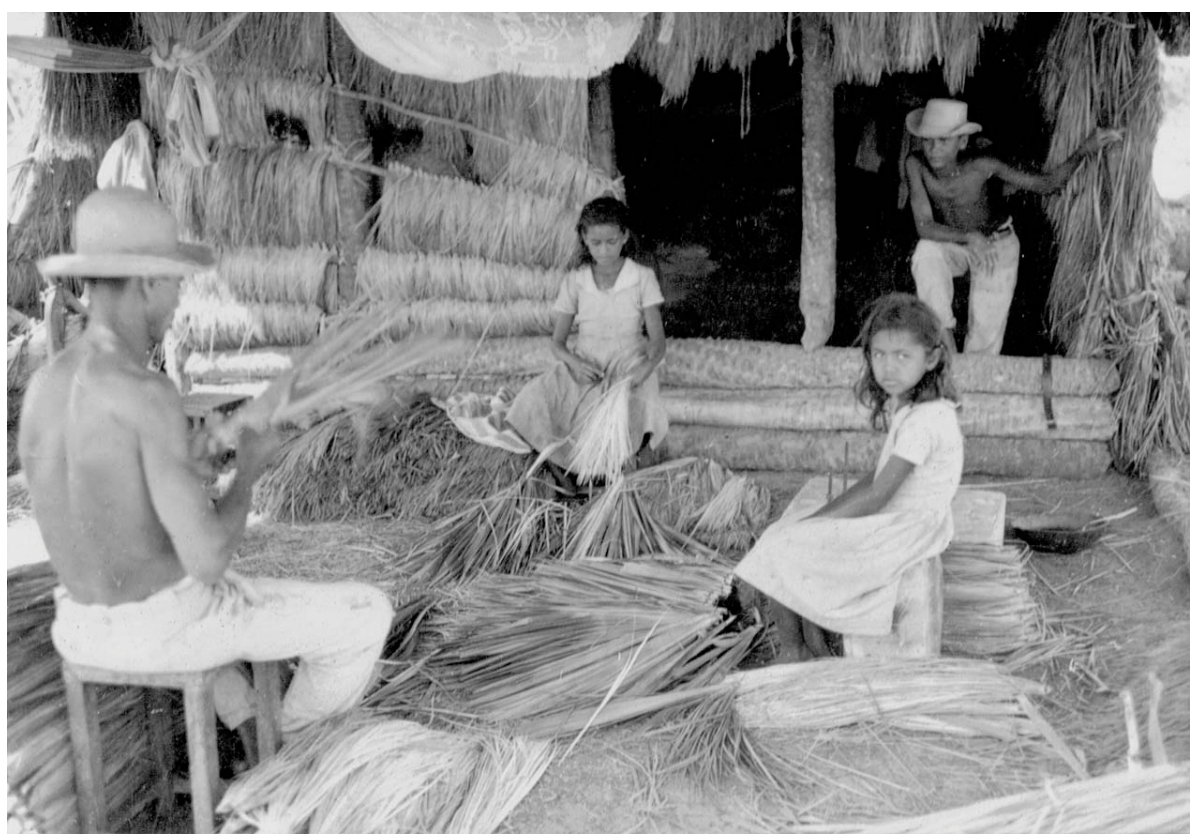

Moça batendo folha de carnaúba em Cabeceiras do Piauí (PI), 1957

A atividade de exploração da palha da carnaúba comumente envolve todo o núcleo familiar, no qual são estabelecidas ações combinadas de trabalho que se estendem a parentes e vizinhos em rede de solidariedade e reciprocidade, que compõem estratégias de subsistência e sobrevivência de população em comunidades rurais e atendem às concepções do que é justo e necessário, ou não, e dão sentido a interesses econômicos peculiares. Para o historiador italiano Giovanni Levi: 
[...] não se trata de identificar transações presumivelmente altruísta, modeladas sobre o padrão da assistência prestada e, se possível e necessário, recompensada, mas sem expectativa de uma contrapartida material direta de transações diretas nas quais a compensação seja um equivalente consuetudinário e instantâneo do bem recebido. Em uma sociedade que não tem uma definição clara da determinação dos valores econômicos, não conhece um mercado impessoal e autorregulado, os problemas de definição do preço justo e do salário justo são complexos e remetem continuamente ao conceito de equidade. Não se trata de deduzir o valor dos bens intercambiados de uma determinação definida no intercâmbio, nem de uma característica intrínseca dos bens, mas de construir um sistema de câmbio no qual os valores estejam determinados pelas características específicas dos que intercambiam, ao ponto de que um mesmo bem adore valores distintos segundo quais sejam as pessoas que entram em transação. ${ }^{19}$

As práticas econômicas pensadas por Giovanni Levi, trazidas para o nosso estudo, nos faz refletir sobre as múltiplas relações e interesses em torno da economia do extrativismo da carnaúba. De um lado, interesses econômicos voltados para o mercado de exportação, evidenciado nos fragmentos das Mensagens de Governo ao Presidente da República, de outro, os trabalhadores extrativistas que definem o próprio ritmo de trabalho e se organizam em moldes tradicionais do sistema de parceria, ou arrendamento. $\mathrm{O}$ quadro abaixo evidencia o crescimento dos números de parceiros e arrendatários no Piauí, em cenário de extrema pobreza no estado, tanto para os produtores rurais, quanto por aqueles que não possuíam terra.

Tabela 01: Número de parceiros e arrendatários em estabelecimentos de menos de 10 ha.

\begin{tabular}{|c|c|c|}
\cline { 2 - 3 } \multicolumn{1}{c|}{} & 1950 & 1970 \\
\hline Piauí & 51.110 & 413.275 \\
\hline
\end{tabular}

Fonte: Carvalho $(1978)^{20}$

As relações estabelecidas entre as famílias de trabalhadores extrativistas e o proprietário da terra são tão opressoras quanto aquelas vivenciadas por estes sujeitos em condição de migrantes trabalhando em fazendas nos confins do País. Em pesquisas para a tese de doutoramento ${ }^{21}$, evidenciamos que o crescimento das migrações bate-e-volta de trabalhadores rurais do estado do Piauí para outras regiões em busca de trabalho se fez em contexto de aumento de crise de esfacelamento do sistema de parceira, após a crise no setor agrário do estado.

19 LEVI, 2009, p. 80-81.

20 CARVALHO, 1978.

21 ROCHA, 2015. 
Comumente, a parceria era estabelecida entre o proprietário e o sujeito que já vivia naquelas terras na condição de morador, que alternavam a lida na roça com as atividades extrativas. Em contexto citado, de impulsionamento das migrações bate-e-volta, no primeiro momento para a região da Amazônia nas décadas de 1970 e 1980, as atividades combinadas de trabalho que expressam uma interdependência entre homens e mulheres se recriam e fazem fortalecer as relações de reciprocidade e solidariedade, indispensáveis para a sobrevivência dessas famílias. No caso específico das atividades extrativas da carnaúba, cuja exploração permaneceu em menor escala em tempos de crise, as relações de parentesco que atravessam a atividade endossam a naturalização da exploração e submissão dos trabalhadores, em muitos casos viabilizadas por relações forjadas de parentesco e compadrio.

\section{ENTRE A EXPLORAÇÃO E A ESCRAVIDÃO}

Embora até as décadas de 1970 e 1980, comprovadamente, não pesem as regras internacionais para pensar as condições de trabalho no país, compreendemos que antes não existiam ferramentas legais para o combate ao trabalho escravo no país além do art. 149 do Código Penal de 1940, "Reduzir alguém a condição análoga à de escravo: Pena-reclusão de dois a oito anos"22. É preciso considerar que este aparato legal, por si só, já se apresentava como um ponto de partida para promover algum tipo de disputa com os fazendeiros e tornar a análise imprescindível para o início do debate entre parlamentares.

Entre os Tratados Internacionais que naquelas circunstâncias o Brasil já era signatário, chamo atenção particular para a Convenção $n^{\circ} 29^{23}$ da OIT sobre o trabalho forçado (1930), visto que não se pode também negar que a OIT se manteve atuante no debate sobre trabalho forçado nos países da América Latina. O fato de que o Estado brasileiro já integrava o sistema internacional de Nações e vários organismos que tratavam do tema do trabalho forçado, além da OIT já mencionada e a Sociedade das Nações, nos faze refletir sobre a invisibilidade quanto à existência de trabalho escravo no país, ou trabalho forçado, como é tipificado pela OIT. Ademais, cabe considerar que, no contexto de criação do art. 149, o Estado estava atuando como aliciador de trabalhadores para a campanha "Borracha para a Vitória"24.

Seu Valdinar Oliveira ${ }^{25}, 58$ anos, derrubador da palha da carnaúba no município de Luís Correia, no litoral do Piauí , disse-nos em entrevista realizada em 2015 que percebia mudanças em relação ao tempo em que começou a trabalhar nessa atividade, também praticada por seus pais e avós. $\mathrm{O}$ trabalhador

22 CÓDIGO PENAL, 1940.

23 ORGANIZAÇÃO INTERNACIONAL DO TRABALHO. Convenção nº 29.

24 FERRERAS, 2017.

25 OLIVEIRA, 2015. 
se manifestou surpreso em relação à possibilidade de acesso aos direitos trabalhistas, anunciado após as fiscalizações realizadas em junho daquele ano, pelo Ministério Público do Trabalho - MPT/PI e Superintendência Regional do Trabalho e Emprego - SRT/PI.

Ao ser questionado se ele percebia diferenças, ele nos disse: “não, só que naquele tempo trabalhava todo mundo, pegava aquele monte de gente e trabalhava, não tinha nada desse negócio de carteira embargada [registrada, assinada] né, hoje tá todo mundo [...]"26. E, como complemento, disse que esse revés se deu recente, a partir do mês de junho.

Quando lhe perguntamos sobre o cotidiano do trabalho, as dificuldades e os danos provocados à saúde do trabalhador, ele respondeu: "pra falar a verdade para quem quer enfrentar a vida não tem nada difícil”. E complementou, "aí a pessoa que banca o serviço que quer fazer. É um serviço de pouco risco de vida, porque você tá puxando aquela palha lá de cima, aquele negócio de repente [...] é fatal. Mas a pessoa vai fazer o quê...?" ${ }^{27}$.

A fala de Seu Valdinar converge com dito em entrevistas coletivas com membros do Sindicato dos Trabalhadores e Trabalhadoras Rurais - STTR do município de Luís Correia. Há uma naturalização da exploração, e a associação da prática ao trabalho escravo pode ser sentida com a chegada das primeiras fiscalizações. $\mathrm{O}$ entrevistado reforçou o discurso sobre as mudanças no tempo e no acesso aos direitos do trabalhador anunciadas pelos novos tempos vivenciados, para quem, de tanto ser explorado e submetido à condição de trabalho escravo, encarar a atividade como relação de trabalho com garantia de direitos é algo surpreendente e distante de sua realidade. $\mathrm{E}$ a esse respeito, o simples uso de um capacete como uma norma de segurança no trabalho causou espanto ao Seu Valdinar.

Naquele tempo num tinha nada, num tinha problema nenhum, o pessoal ia pro mato do jeito que dava, né. Pegava um saco de roupa, passava uma semana trabalhando fora, na mata, todo mundo dormia na mata, já hoje não tem mais isso. Aquele tempo era bebendo água de cacimba né, água salobra. Hoje não, a pessoa vai, todo mundo leva as garrafas d'água ${ }^{28}$.

O tempo tratado pelo entrevistado é compartilhado com as experiências vivenciadas por seus pais e avós, nas mesmas terras onde ainda vive, e é retratado como um tempo de inexistência da Lei para aquele tipo de trabalho, que, expressa o desconhecimento de seus direitos, bem como do potencial econômico do pó da palha da carnaúba, por parte dos trabalhadores.

A sequência de fotos abaixo, dos procedimentos de corte, transporte e secagem da palha de carnaúba, são registros de flagrante realizados no município 
de Luís Correia, no ano de 2014, em operação do MPT e STRE, e evidenciam similaridades em relação à mesma atividade executada nos anos de 1950 (ver imagens 1 e 2 ).

\section{Imagens: 3, 4, 5 e 6 (ordem vertical da esquerda para a direita)}

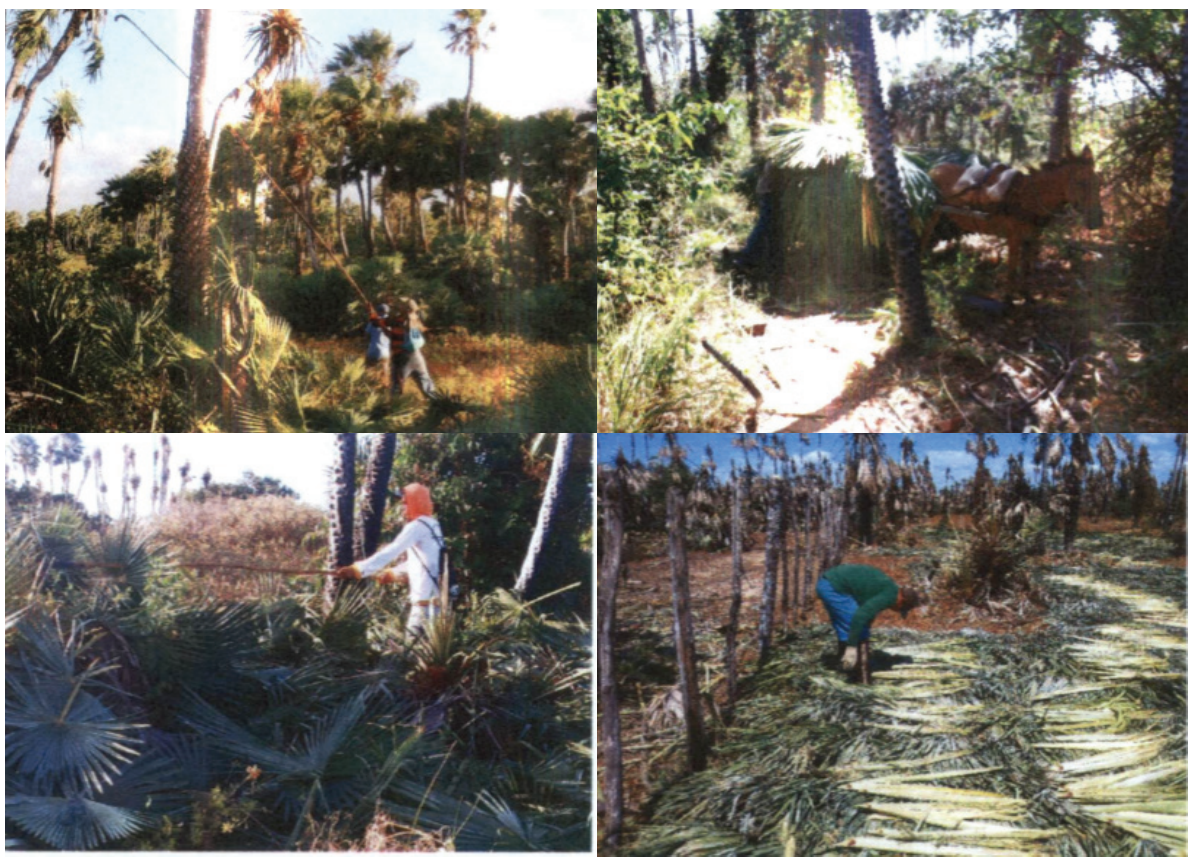

Fonte: STRE, 2014

A possibilidade de acesso aos direitos trabalhistas causou surpresa e estranhamento entre os trabalhadores extrativistas. Para além das conquistas históricas dos trabalhadores rurais na luta por acesso aos direitos trabalhistas, o extrativismo se mantém como uma atividade de caráter informal sem avanço em relação às normas de saúde e segurança no trabalho.

Entendemos que a extinção da escravidão legal no final do século XIX abriu brechas para estratégias de formas de exploração no trabalho próprias do capitalismo, que, em vários aspectos, se aproximavam das condições de trabalho características da escravidão, denunciadas no Código Penal de 1940. Como dito, o artigo 149 sanciona a redução de uma pessoa a condições análogas às de escravo com pena de dois a oito anos de prisão; o Art. 207 sanciona o aliciamento de trabalhadores com o fim de levá-los para outra localidade do território nacional com pena de dois meses a dois anos de prisão e multa; e o Art. 203 sanciona a frustração, mediante fraude ou violência, do gozo de direito assegurado pela legislação do trabalho com pena de multa e prisão. 
Em entrevista sobre a atuação do MPT local em relação aos casos flagrantes de trabalho escravo, o procurador Edno Moura nos disse:

A palha de carnaúba tem uma cadeia muito intrincada. Na verdade, quem se beneficia é a indústria da cera de carnaúba. $\mathrm{Na}$ indústria da cera existem industriais piauienses e cearenses, como a indústria da cera está concentrada nos dois estados. Mas quem faz a contratação mesmo é um outro trabalhador rural, que normalmente é financiado por alguém que comercializa o pó ou pela própria indústria, diretamente. Então normalmente a gente encontra pessoas que arregimentam os trabalhadores e arrendam a área para fazer a extração [...]. Em uma situação dessas de operação a gente já conseguiu fazer $\mathrm{o}$ vínculo com a própria indústria, a indústria diretamente e o arrendatário ${ }^{29}$.

Entre a configuração da cadeia produtiva da cera de carnaúba, atravessou os tempos e permanece como uma atividade que não sofreu transformações na forma de organização, nem tampouco nas relações estabelecidas na unidade produtiva. As relações familiares são predominantes e se apresentam como um entrave para o reconhecimento da exploração e trabalho escravo. No Piauí, as operações de combate ao trabalho escravo, em particular em atividades ligadas ao agronegócio, carvoarias e na extração do pó da carnaúba, foram iniciadas e são apresentadas de forma mais atuante a partir do ano de 2004.

Em levantamento realizado para pesquisa Raice ${ }^{30}$ no ano de 2015, foram identificadas apenas quatro operações em áreas de extração da palha de carnaúba, entre as quais obtivemos acesso a dois relatórios de operações realizadas em áreas de extração, dos municípios de Assunção do Piauí, na região centro-norte do estado e fronteira com o estado do Ceará, e Luís Correia, no litoral do estado. Os trabalhadores que compunham a mão de obra eram de origem local e do estado do Ceará. Estes atravessam a fronteira semanalmente e o fazem por intermédio de um arregimentador, que se trata de um conterrâneo ou intermediário de origem local responsável pela empreitada, arrendamento da terra por um período de quatro a cinco meses para retirada da palha, transporte e extração do pó. Os relatórios nos deram indícios de que as indústrias de beneficiamento da cera utilizam o arregimentador como intermediário para a contratação dos trabalhadores. Nesses casos, a empresa costuma adiantar valores em dinheiro ao intermediário e recebe o pó cerífero para o efetivo abatimento dos valores fornecidos.

Sobre as narrativas em torno da aceitação ou não denúncia dos trabalhadores em relação às condições de trabalho, pesam as relações de parentesco. Nesse sentido, apresentamos os fragmentos de falas de dois membros do STTR de Luís Correia, Piauí, ao serem questionados sobre a longevidade da atividade na região:

29 MOURA, 2015.

30 ROCHA, 2016. 
Sim é [confirmou a longevidade da atividade na região]. A extração de carnaúba é, né seu Trajano? Mas como as pessoas já fizeram adaptação do corpo nesse trabalho eles já se acostumaram e não veem como exploração, escravidão. Por isso que eu pergunto a vocês. Qual a definição, conceito de trabalho escravo para vocês? Esse trabalho é considerado pra vocês? Pra nós no caso? A gente sabe que é $[\ldots]^{31}$.

Em complemento à sua fala, José Magno comentou:

Mas o pior de tudo é que o Ministério do Trabalho não considera [trabalho escravo], embora que seja trabalho de escravidão, como uma coisa que não está dentro da lei é. Se você for meu parente, se for filho, irmão, você pode trabalhar que não tem nada a ver, ele não considera, no que ele embargar a carteira tanto faz [...]. Eu tive lá com João Louro eu vi lá $[\ldots]^{32}$.

Como evidenciado, a atividade da palha da carnaúba tem bases de sustentação na família e nas relações de parentesco que estão para além do caráter consanguíneo. $\mathrm{O}$ aspecto familiar da atividade favorece a manutenção das redes de exploração que, não raro, se estendem ao trabalho escravo.

\section{CONSIDERAÇÕES FINAIS}

A realidade da escravidão contemporânea se inscreve numa das tantas faces cruéis do capitalismo agrário. As relações de trabalho estabelecidas na atividade extrativa da cera de carnaúba, viabilizadas pelo atravessador ${ }^{33}$, ocultaram fortes interesses comerciais. No dizer de José de Sousa Martins, "A servidão moderna, em nossa sociedade, é viabilizada e revigorada pelo poder da tradição e pela função que ela exerce no processo de desenvolvimento do capitalismo entre nós" ${ }^{34}$. São faces do caráter profundamente contraditórias do capitalismo, cujos efeitos se reproduzem historicamente.

É importante considerar as condições históricas vivenciadas pelo homem do campo para compreender a forma peculiar como percebem suas condições de trabalho e vida. Em estudos já realizados sobre a escravização de migrantes, evidenciamos um tipo de organização dos trabalhadores em processos de resistência e denúncia quanto às condições de trabalho a que são comumente impostos $^{35}$. Nesses casos, percebemos uma relação continuada e pedagógica dos trabalhadores com os dispositivos legais de combate à escravidão e a própria legislação trabalhista, que decorrem de suas vivências e diálogos com

31 SILVA, 2015.

32 MAGNO, 2015.

33 Trata-se de um parente ou alguém da comunidade, comumente responsável pelo arrendamento da área para exploração e contratação dos trabalhadores. Após a extração do pó cerífero, o atravessador o repassa à indústria da cera. A presença do atravessador, que em muitos casos recebe o adiantamento para arrendamento da área de exploração, pode eximir o empresário das responsabilidades trabalhistas.

34 MARTINS, 2002.

35 ROCHA, 2015. 
instituições e organismos comprometidos com o debate sobre o trabalho forçado e escravidão contemporânea. Por outro lado, a escravidão na cadeia produtiva da cera da carnaúba se apresenta como uma descoberta recente e ainda pouco debatida, ocultada pelo histórico de informalidade e pelo discurso de utilização predominante de mão de obra familiar na atividade. A esse contexto, soma-se o medo sentido pelos extrativistas diante das incertezas em relação ao mundo do trabalho, a concepção moral de trabalho, o desconhecimento de direitos básicos do trabalho e direitos humanos.

\section{REFERÊNCIAS}

BRASIL. Acidentes do Trabalho e outras providências. Decreto-Lei n ${ }^{\circ} 24.637$, 10 de jul. de 1934.

CARVALHO, João Carlos Monteiro de. Tendências recentes do campesinato brasileiro. IN: Camponeses no Brasil. Petrópolis: Vozes, 1978.

CÓDIGO PENAL, 1940. Disponível em: http://www.amperj.org.br . Acesso em 11. Dez. 2009.

FERRERAS, Norberto O. Trabalho Análogo a de Escravo: debates em torno de um conceito transacional. In: FIGUEIRA, Ricardo Rezende. PRADO, Adonia Antunes.

GALVÃO, Edna Maria (Org.). Trabalho Escravo Contemporâneo: estudo sobre ações e atores. $1^{\text {a }}$ Ed. Rio de Janeiro: Mauad X, 2017.

CDVDH, CPT. Entre Idas e Vindas: novas dinâmicas de migração para o trabalho escravo. 1 ed. São Paulo: Urutu-Branco, 2017.

FONTENELE, Hamanda Machado de Meneses. Terra Rica, Homem Pobre: Aspectos Socioeconômicos piauienses nos tempos áureos da cera de carnaúba (1930-1960). Monografia (Licenciatura Plena em História) - Universidade Estadual do Piauí, 2018.

JORNAL O PIAUÍ, 13 de junho de 1951 p. 02.

LEVI, Giovanni. Economia camponesa e o mercado de terra no Piemonte do Antigo Regime. In: Exercícios de micro-história. OLIVEIRA, Mônica Ribeiro de; ALMEIDA, Carla Maria Carvalho de (org.). $1^{\text {a }}$ Ed. Rio de Janeiro: Editora FGV, 2009.

MARTINS, José de Sousa. A Sociedade vista do Abismo: novos estudos sobre exclusão, pobreza e classes sociais. Petrópolis, RJ: Ed. Vozes, 2002.

MAGNO, José. Entrevista realizada por Cristiana Costa da Rocha em 29.09.2015 no município de Luís Correia.

MOTA, Walter. Sobre as necessidades de mecanização da produção de cera de carnaúba. In: CORREIA, Benedito Jonas; LIMA, Benedito dos Santos (org.). 
O livro do centenário da Parnaíba. 1 ed. Parnaíba: Gráfica América, 1946. p. 342-343.

MOURA, Edno de Carvalho. Entrevista realizada por Cristiana Costa da Rocha em 09.09.2015 no município de Teresina.

ORGANIZAÇÃO INTERNACIONAL DO TRABALHO. Convenção n ${ }^{\circ} 29$. Disponível em <http://www.oitbrasil.org.br. Acesso em: 10. out. 2009.

OLIVEIRA, Valdinar Oliveira e Maria Lúcia de Oliveira. Entrevista realizada por Cristiana Costa da Rocha em 15.10.2015 no município de Luís Correia.

PARNAÍBA. Almanaque da Parnaíba, 1937, p. 183.

PIAUÍ. Diário Oficial do Estado. Relatório de Governo apresentado ao presidente Getúlio Vargas pelo interventor Landry Salles Gonçalves - 19311935, Teresina: Imprensa Oficial, p 114.

PIAUÍ. Diário Oficial do Estado. Relatório de Governo apresentado pelo governador Pedro de Almendra Freitas (1952)

PIAUÍ. Diário Oficial do Estado. Relatório de Governo apresentado pelo interventor federal Leônidas de Castro Melo ao Presidente Getúlio Vargas (1938), p10.

QUEIROZ, Teresinha de Jesus. Economia Piauiense: da pecuária ao extrativismo. $2^{\mathrm{a}}$ Ed. Teresina: EDUFPI, 1998.

ROCHA, Cristiana Costa. A vida da Lei, A Lei da Vida: conflitos pela terra, família e trabalho escravo no tempo presente. 2015. Tese (Doutorado em História) - Universidade Federal Fluminense, Niterói, RJ.

ROCHA, Cristiana C. Rede de Ação Integrada para Combater a Escravidão Raice. Relatório de Pesquisa Piauí apresentado à CPT, 2016.

. FERRERRAS, Norberto (org.). Trabalho e Trabalhadores no Brasil: experiências, deslocamentos, modalidades e resistência. - Niterói: EDUFF, 2017.

STRE. Relatório de Fiscalização (Pontes Indústria de Cera do Piauí, Ltda Parnaíba, PI). MTE: 13.08 a 05.09.2014, p.16.

SILVA, Valdemir Pereira da. Entrevista realizada por Cristiana Costa da Rocha em 29.09.2015 no município de Luís Correia.

THOMPSON, E. P. Costumes em Comum: estudos sobre a cultura popular tradicional. São Paulo: Companhia das Letras, 1998.

Recebido em: 04/09/2019.

Aprovado em: 15/12/2020. 
